\title{
Role of topical beta blockers in regression of infantile capillary hemangioma
}

\author{
Murtaza Sameen Junejo ${ }^{1}$, Rebecca $a^{2}$ \\ Maria Nazish Memon ${ }^{3}$, Sajida Parveen Shaikh ${ }^{4}$
}

\begin{abstract}
Objective: To observe efficacy of Timolol maleate $0.5 \%$ by topical and surface application in infantile superficial capillary hemangioma of eyelid.

Methods: This multi-centered clinical case series was carried out at Ophthalmology Department of Bilawal Medical College and Institute of Ophthalmology, LUMHS, Jamshoro from November 2019 to May 2020. We included 14 subjects. All the patients were subjected to detailed clinical examination. Before starting the topical beta blockers, the enrolled subjects had obtained the expert opinion by pediatrician to rule out any preexisting developmental cardio vascular disease. Topical beta blockers $0.5 \%$ drops were thus started with, against the ongoing finding of superficial capillary hemangioma of eyelid.

Results: There was significant regression in size of infantile hemangioma after treating with topical timolol maleate $0.5 \%$. We included 14 subjects in this study. Mean $\pm \mathrm{SD}$ age of patients was 4.94 . Complete regression was seen in 08 subjects at the end of 12 weeks (64\%) while 03 were completely cured at 08 weeks (21\%) and 01 patient lost follow up with us. No significant ocular and systemic side effects were noted.

Conclusion: Topical timolol maleate $0.5 \%$ can be the first-line treatment modality for superficial capillary hemangiomas due to its better safety and efficacy.
\end{abstract}

KEYWORDS: Capillary hemangioma, Superfical Hemangioma, Topical timolol maleate $0.5 \%$.

How to cite this:

doi: https://doi.org/10.12669/pjms.37.7.4317

Junejo MS, Rebecca, Memon MN, Shaikh SP. Role of topical beta blockers in regression of infantile capillary hemangioma. Pak J Med Sci. 2021;37(7):1935-1938. doi: https://doi.org/10.12669/pjms.37.7.4317

This is an Open Access article distributed under the terms of the Creative Commons Attribution License (http://creativecommons.org/licenses/by/3.0), which permits unrestricted use, distribution, and reproduction in any medium, provided the original work is properly cited.

\section{INTRODUCTION}

Dr. Murtaza Sameen Junejo, FCPS.

Dr. Rebecca, MBBS.

Dr. Maria Nazish Memon, FCPS, FCPS (Paediatirc Ophthalmology)

4. Dr. Sajida Parveen Shaikh, FCPS.

1-4: Department of Ophthalmology,

Liaquat University of Medical and Health Sciences,

Jamshoro, Pakistan.

Correspondence:

Dr. Murtaza Sameen Junejo, FCPS.

Department Of Ophthalmology,

Liaquat University of Medical and Health Sciences,

Jamshoro, Pakistan.

Email: drmurtazasameen@gmail.com

* Received for Publication

* $1^{\text {st }}$ Revision Received:

* $2^{\text {nd }}$ Revision Received:

* Final Revision Accepted:
February 22, 2021

June 7, 2021

June 14, 2021

July 8, 2021

Infantile hemangiomas (IH) are benign proliferation of endothelial cells mostly arising in first 08 weeks of life. ${ }^{1,2} \mathrm{IH}$ are most frequent benign tumors of infancy. The incidence in one year old children is $5-10 \%$ in first year of life. Preterm infants with low birth weight have relatively higher risk of about $23 \% .^{2}$

The cycle of disease is characterized by early proliferative phase, followed by involution and results in complete regression in most cases. During first few months aged, the lesion grows aggressively, followed by stabilization. Involution is complete in most youngsters by four years of age. ${ }^{3}$ Mostly lesions are benign, regress spontaneously, but approximately $10 \%$ often site dependent can cause serious complications like Astigmatism and 
Amblyopia. Thanks to cosmetic disfigurement, parental distress, and morbidity, appropriate management are much needed. ${ }^{4,5}$

Previously hemangiomas were treated with ultrapotent topical corticosteroids, which were potent but were causing side effects like skin hypopigmentation and atrophy ${ }^{6-8}$ Imiquimod 5\% cream topically has been used as an alternate but it also has side effects like crusting and scars. ${ }^{9-12}$

Topical $\beta$-blockers timolol maleate $0.5 \%$ are best substitute in managing superficial IHs asthey will improve the therapeutic efficacy and reduce systemic adverse effects of beta blockers. ${ }^{13}$ However, systemic propranolol with a dose of two $\mathrm{mg} / \mathrm{kg} /$ day is additionally used but can cause adverse systemic side effects. ${ }^{14,15}$

Topical timolol has been reported to inhibit the expansion and promote regression of superficial $\mathrm{IH}^{\prime}$ s. ${ }^{16}$ So during this study we shall evaluate the safety and efficacy of $0.5 \%$ timolol maleate solution for superficial IH in early age bracket.

\section{METHODS}

This multi-centered case series was conducted at Bilawal Medical College and Institute of Ophthalmology, LUMHS, Jamshoro from November 2019 to May 2020 after approval from ethical committee (LUMHS/REC/-828). Fourteen patients aged two months to 18 months were included during this study after an informed written consent.

All the subjects underwent detailed ocular and systemic examination and patients having superficial capillary hemangioma of eyelid were included. Subjects having hypertension, visceral involvement, respiratory problem \&

Table-I: Clinical characteristics of patients with capillary hemangioma.

\begin{tabular}{lc}
\hline Characteristics & Value \\
\hline Age (Months) & 4.94 months \\
Gender & \\
Male & $5(35.7 \%)$ \\
Female & $9(64.3 \%)$ \\
Regression & \\
02 weeks & $1(7 \%)$ \\
08 weeks & $3(21 \%)$ \\
12 weeks & $8(64 \%)$ \\
\hline
\end{tabular}

cardiovascular abnormalities were excluded from the study. Opinion of pediatrician to rule out developmental cardiovascular abnormalities was obtained before the commencement of treatment. Topical Timolol Maleate $0.5 \% \quad 2$ drops were applied over the lesion twice each day. Follow up was done at two weeks, eight weeks and 12 weeks respectively during which color and size of lesion were assessed. Statistical analysis was through with help of SPSS version 21.0. p-value was not calculated due to single group study.

\section{RESULTS}

Fourteen (14) subjects received timolol maleate with a total mean \pm SD age of 4.94 (Male $=6.5$ and female mean age $=4.08$ months, respectively. Gender distribution of patients was $64 \%$ male and $36 \%$ female. The most common indication of treating IH's was to prevent cosmetic disfigurement, ulceration, astigmatism and amblyopia. Clinical characteristics of patients are mentioned in Table-I. Complete regression of lesion was observed in 08 subjects at 12 weeks $(64 \%)$, while $03(21 \%)$ children got regression at 08 weeks. Unfortunately, one child developed ulceration at 02 weeks of start of timolol maleate $(7 \%)$ whereas one got regression at 02 weeks and one patient lost follow up with us $(7 \%)$ mentioned in Chart-II. No adverse ocular and systemic effects were seen. Photographs of patients taken after consent, before and after treatment are given in Fig.1 and 2.

\section{DISCUSSION}

Inafantile hemangiomas grow in early period of life that mostly resolves spontaneously. The proliferative phase commences during a week or two of life, that's followed by a plateau phase.

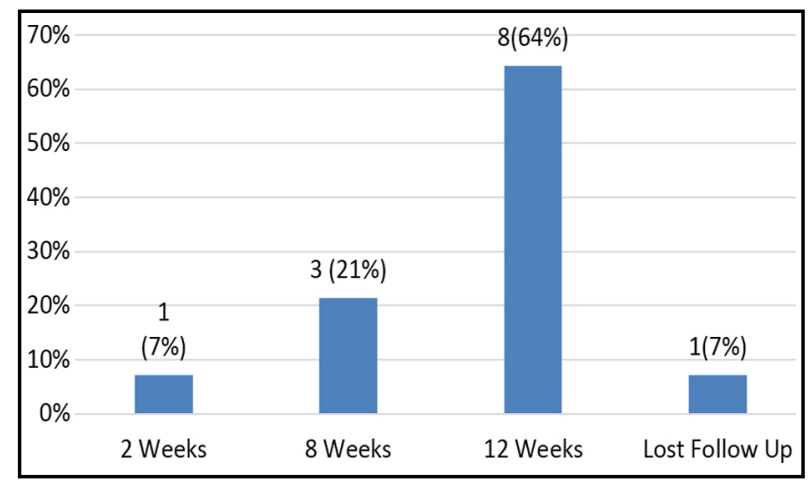

Chart.1: Regression of hemangioma after treatment with Timolol Maleate $(\mathrm{n}=14)$. 


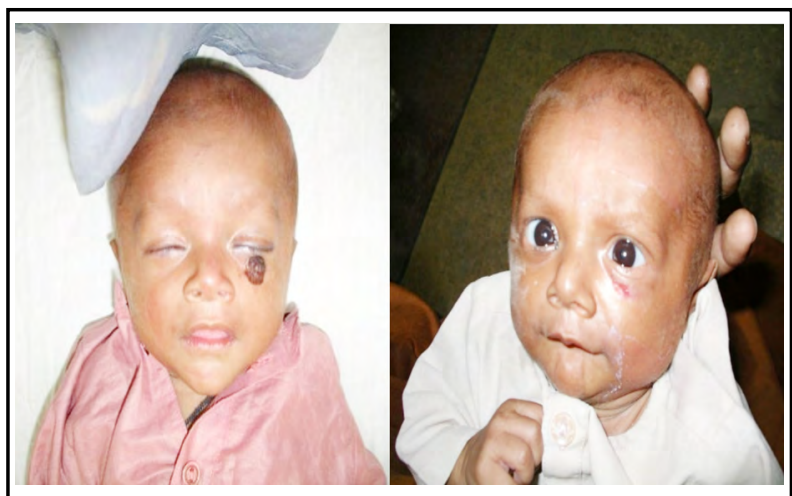

Case-1: Before treatment

08 weeks after treatment

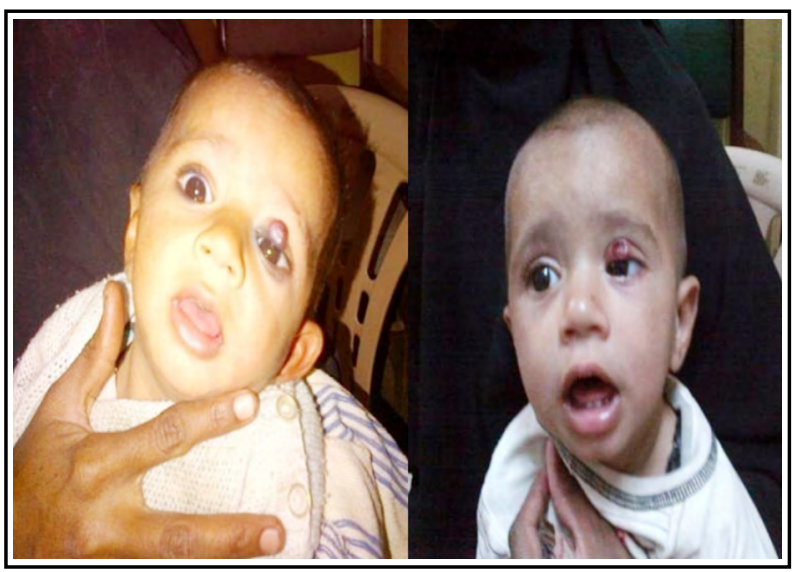

Case-2: Before Treatment

02 weeks after treatment (LEFT EYE)

(Ulcerated)

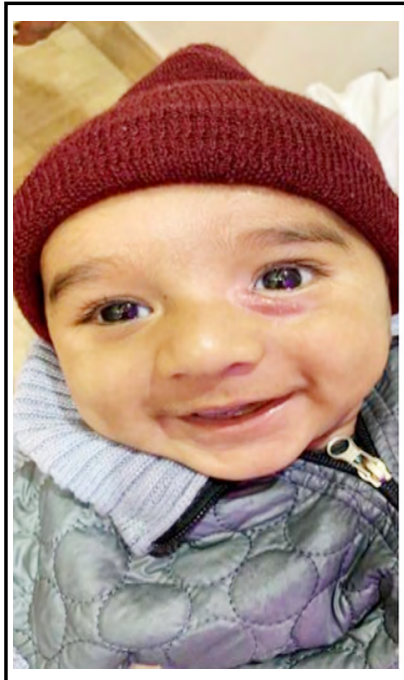

Case-3: Before Treatment (Left Eye)

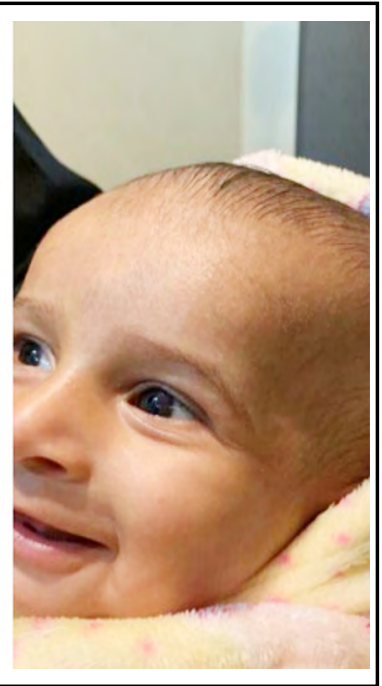

08 weeks after treatment

The involution phase is noticed to be commenced at a primary year of life and remains until 4-6 years aged. In our study, the initial age for the looks of IH's was eight weeks, as compared with previous studies. Xu et al found that the therapeutic response of youngsters who started treatment with propranolol ointment had a big difference. ${ }^{10} \mathrm{Yu}$ et al. noted that patients treated with timolol before the age of 06 months had higher regression rates. This is often in lieu with our study results.

Ariwibowo, Danarti et al. and associates found that Timolol maleate $0.5 \%$ the answer was better than corticosteroids in reducing the dimensions of superficial IH. ${ }^{10,14,17-24}$ Our study also showed reduction in size,colour and shape of superficial infantile hemangiomas in approximately 08-12 weeks after the initiation of treatment.

Regression of $\mathrm{IH}^{\prime}$ s using $0.5 \%$ timolol maleate drops occurred before spontaneous regression which occurred at 9-12 months. ${ }^{18,25}$ In our study, there was complete regression in 08 cases upto 12 weeks while 03 cases regressed at 08 weeks from the onset of treatment. Spontaneous regression of $\mathrm{IH}^{\prime}$ s in comparison with hemangiomas treated with timolol maleate $0.5 \%$, morphological differences were observed. In later the regression of endothelial cells with apoptosis was observed. ${ }^{24,25}$ We didn't observe the histological changes in our studies but the morphological outcomes were noteworthy and appreciable.

Despite our success of treating IH's with topical timolol maleate $0.5 \%$, the underlying mechanism of timolol maleate remains elusive. Further work should be administered and comparison of regression between children and adults should be investigated on large scale.

Limitations of the study: we could not consider the presence of multiple and deep hemangiomas and their regression with topical timolol maleate $0.5 \%$. Moreover, we measured short term post treatment effect of 12 weeks.

\section{CONCLUSION}

Topical timolol maleate $0.5 \%$ instead of oral propranolol could be the first-line approach for superficial capillary hemangiomas due to its good efficacy and improved safety. However, a comparative study between children and adult's regression of hemangiomas must be conducted and evaluated at a larger scale.

Conflict of Interest: There is no conflict of interest to disclose.

Grant Support E Financial Disclosures: None. 


\section{REFERENCES}

1. Park KH, Jang YH, Chung HY, Lee WJ, Kim DW, Lee SJ. Topical timolol maleate $0.5 \%$ for infantile hemangioma; it's effectiveness and/or adjunctive pulsed dye laser - single center experience of 102 cases in Korea. J Dermatolog Treat. 2015;26(4):389-391. doi: 10.3109/09546634.2014.990412

2. Wu HW, Liu C, Wang X, Zhang L, Yuan W, Zheng JW, et al. Topical Application of $0.5 \%$ Timolol Maleate Hydrogel for the Treatment of Superficial Infantile Hemangioma. Front Oncol. 2017;7:137. doi: 10.3389/fonc.2017.00137

3. Meng XY, Yu XH, Cao RY, Shang J, Liu LP. Oral Propranolol Combined with Topical Timolol Maleate for the Treatment of Compound Infantile Hemangioma in Parotid Region. JHard Tissue Biol. 2018;27(2):165-168. doi: 10.2485/jhtb.27.165

4. Boos MD, Soccio LC. Experience with topical timolol maleate for the treatment of ulcerated infantile hemangiomas (IH). J Am Acad Dermatol. 2016;74(3):567570. doi: 10.1016/j.jaad.2015.10.021

5. Puttgen K, Lucky A, Adams D, Pope E , McCuaig C, Powell J , et al. Topical Timolol Maleate Treatment of Infantile Hemangiomas. Pediatrics. 2016;138(3):e20160355. doi: 10.1542/peds.2016-0355

6. Xue K, Hildebrand GD. Topical timolol maleate $0.5 \%$ for infantile capillary haemangioma of the eyelid. Br J Ophthalmol. 2012;96(12):1536-1537. doi: 10.1136/ bjophthalmol-2012-302396

7. Jha AK, Kumar P, Anand V. Topical Timolol: A Novel Approach in Infantile Hemangioma. Skinmed. 2015;13(6):429-431.

8. Calvo M, Millan CG, Villegas C, Casado AF, Buron I.Topical timolol for infantile hemangioma of the eyelid. Int J Dermatol. 2013;52(5):603-604. doi: 10.1111/j.13654632.2011.05290

9. Bhat YJ, Yaseen A, Hassan I. Topical timolol maleate: An effectual and safe recourse for infantile hemangiomas. Indian Dermatol Online J. 2016;7(2):124-125. doi: 10.4103/2229-5178.178076

10. Xu DP, Cao RY, Tong S, Xue L, Sun NN, Wang XK. Topical timolol maleate for superficial infantile hemangiomas: an observational study. J Maxillofacial Surg. 2015;73(6):10891094. doi: 10.1016/j.joms.2014.12.026

11. Zheng JW, Wang XK, Jiang CH, Qin ZP, Fan XD, Yang YW, et al. Chinese expert consensus on the use of topical timolol maleate treatment of infantile hemangiomas. Shanghai Kou Qiang Yi Xue. 2016;25(6):744-747.

12. Painter SL, HildebrandGD.Topical timolol maleate $0.5 \%$ solution for the management of deep periocular infantile hemangiomas. J Aapos. 2016;20(2):172-174. doi: 10.1016/j. jaapos.2015.11.012

13. Chambers CB, Katowitz WR, Katowitz JA, Binenbaum G. A controlled study of topical $0.25 \%$ timolol maleate gel for the treatment of cutaneous infantile capillary hemangiomas. Ophthalmic Plast Reconstr Surg. 2012;28(2):103-106. doi: 10.1097/IOP.0b013e318

14. Blanco CC, DominguezMC, Garcia BM, Alvaraz-Santullano CAV, Frohner BB, Fernandez RS, et al. Episcleral infantile hemangioma successfully treated with topical timolol. Dermatologic Therapy. 2015;28(1):22-24. doi: 10.1111/ dth.12173
15. Rizvi SAR, Yusuf F, Sharma R, Rizvi SWA. Management of superficial infantile capillary hemangiomas with topical timolol maleate solution. Semin Ophthalmol. 2015;30(1):6264. doi: 10.3109/08820538.2013.821505

16. Zhang Q, Chantasart D, Li SK. Evaluation of $\beta$-blocker gel and effect of dosing volume for topical delivery. J Pharm Sci. 2015;104(5):1721-1731. doi: 10.1002/jps.24390

17. Danarti R, Ariwibowo L, Radiono S, Budiyanto A. Topical Timolol Maleate $0.5 \%$ for Infantile Hemangioma: Its Effectiveness Compared to Ultrapotent Topical Corticosteroids - A Single-Center Experience of 278 Cases. Dermatology. 2016;232:566-571. doi: 10.1159/000448396

18. Al-Haddad C, El Salloukh NA, El Moussawi Z. $\beta$-blockers in the treatment of periocular infantile hemangioma. Curr Opin Ophthalmol. 2019;30(5):319-325. doi: 10.1097/ ICU.0000000000000591

19. Novoa M, Baselga E, Beltran S, Giraldo L, Shahbaz A, Pardo-Hernandez $\mathrm{H}$, et al. Interventions for infantile haemangiomas of the skin. Cochrane Database Syst Rev. 2018;4. doi: 10.1002/14651858

20. M Hill I, Stefanko N, Drolet BA. Comment on "Doing the math: A simple approach to topical timolol dosing for infantile hemangiomas. Pediatr Dermatol. 2018;35(5):698699. doi:10.1111/pde.13577

21. Painter SL, Hildebrand GD. Topical timolol maleate $0.5 \%$ solution for the management of deep periocular infantile hemangiomas. J AAPOS. 2016;20(2):172-174. doi: 10.1016/j. jaapos.2015.11.012

22. Sipkova Z, Xue K, Mudhar HS, Wagner B, Hildebrand GD. Early and Late Histological and Ultrastructural Findings in Resected Infantile Capillary Hemangiomas Following Treatment with Topical Beta-Blocker Timolol Maleate 0.5\%. Ocul Oncol Pathol. 2018;4(2):100-106. doi: 10.1097/IOP.0b013e31823bfffb

23. Li G, Xu DP, Tong S, Xue L, Sun NN Wang XK. Oral Propranolol with Topical Timolol Maleate Therapy for Mixed Infantile Hemangiomas in Oral and Maxillofacial Regions. J Craniofac Surg. 2016;27:56-60. doi: 10.1159/000510029

24. Hoeger PH, Harper JI, Baselga E, Bonnet D, Boon LM, Atti MCD, et al. Treatment of infantile haemangiomas: recommendations of a European expert group. Eur J Pediatr. 2015;174(7):855-865. doi: 10.1007/s00431-015-2570-0

25. Weissenstein A, Straeter A, Villalon G, Bittmann S. Topical timolol for small infantile hemangioma: A new therapy option. Turk J Pediatr. 2012;54:156-158.

\section{Authors Contribution:}

JMS: conceived, designed and did statistical analysis \& editing of manuscript, is responsible for integrity of research.

JMS, R, MMN: did data collection and manuscript writing.

SPS: did review and final approval of manuscript. 